\title{
Getting out of the shit : toilets and the daily failure of governance in Ghana
}

Sjaak van der Geest and Nelson Obirih-Opareh

\section{(2) OpenEdition \\ Journals}

Electronic version

URL: http://journals.openedition.org/apad/150

DOI: 10.4000/apad.150

ISSN: 1950-6929

Publisher

LIT Verlag

\section{Printed version}

Date of publication: 1 December 2002

\section{Electronic reference}

Sjaak van der Geest and Nelson Obirih-Opareh, « Getting out of the shit : toilets and the daily failure of governance in Ghana », Bulletin de I'APAD [Online], 23-24 | 2002, Online since 15 December 2006, connection on 07 September 2020. URL : http://journals.openedition.org/apad/150 ; DOI : https:// doi.org/10.4000/apad.150

\footnotetext{
This text was automatically generated on 7 September 2020

Bulletin de l'APAD
} 


\title{
Getting out of the shit : toilets and the daily failure of governance in Ghana ${ }^{1}$
}

\author{
Sjaak van der Geest and Nelson Obirih-Opareh
}

The politics of sanitation

In a chapter on the politics of public sanitation between 1920-1940 in Windhoek, Namibia's capital, Gewald (2000:125-144) tries to find an explanation for the fact that "after years of consistent protest and demand on the part of location residents, there was no improvement in public sanitation facilities". The author leads us through a series of graphic quotes from official reports, letters and newspaper clippings about the horrible state of sanitation in the town. In one report from 1925 we read :

"In Windhoek proper there are trenches, but these have developed onto cesspools and the stench coming from them is unbearable. Some of these trenches have been in use (open) for more than a year and the natives complain bitterly of

their filthy conditions. In an experience of 25 years I have never seen anything worse (Gewald $2000: 133)^{\prime \prime}$.

2 A few years later, in 1929, a German newspaper reports :

"... everyone can imagine what odours there are emanating during the hot and rainy season. It is simply unbearable. But it must be endured.... Some of these WCs stand in the middle of the location. Is it surprising that the mortality was so

high of late? Shall we only pay our taxes or should we not also be allowed to elect people to our liking who are concerned about our welfare?

Gewald (2000 : 136)". 
3 Township inhabitants used this situation to protest against the South African colonial administration and those who cooperated with the administration, with only limited success. Gewald concludes by listing four reasons for the authorities' lack of concern about public sanitation. One reason was the "squeamish unease in talking about and dealing with an issue which was generally felt to be below the level of suitable discussion". The second reason referred to the costs involved. The third was that the authorities wanted to discourage the African inhabitants from settling permanently in the town and the last was that they regarded the inhabitants as uncivilised, and not deserving of decent sanitary facilities (Gewald $2000: 144$ ).

Visiting some of the poor neighbourhoods of Accra in the beginning of the 21st century one would imagine oneself walking through Windhoek in 1925. It happened to the two authors of this paper when they went to "inspect" two public toilets in Nima, which is one of the most densely populated suburbs of Accra. The toilets were located in an open space between the houses and the road. Women and children were selling foodstuffs only a few yards away. The same space held two containers for solid waste disposal, which were overflowing. Goats were searching for food in the rubbish on the ground near the containers.

5 Both toilets had 16 squatting holes, eight for each sex. People visiting the toilet had to pay a small amount to the caretaker. In one toilet the pit as completely full and the faeces came up to and over the brim of the holes. Used toilet paper was lying about or had been deposited in large baskets, which were bloc king the passage. The stench was as enormous as the physical and visual filth. For one not used to it, it seemed a miracle that people managed to relieve themselves in such conditions and reappear from the toilet totally spotless.

Close to one of the toilets, in the open air, was a huge container in which night-soil collectors emptied their buckets containing faeces from private houses. The buckets, which they used for their work were standing next to the container.

Little children often did not enter the toilet but defecated behind the toilet in the open space, apparently they could not spend the money or they preferred the "fresh air".

While we were inspecting the place, taking some pictures and discussing the procedures with the caretaker, a group of people assembled around us and expressed their anger and dismay about the sordid sanitation conditions in their neighbourhood. They talked about promises which had been made to them by the city authorities and accused them of total lack of concern and of stealing the money allotted to the construction of proper sanitation facilities.

Governance

If "governance" can be taken to mean, as Stoker (1998) suggests, the successful management of community affairs through a mixing of public, private and voluntary actors, sanitation is an excellent case to test the workings and adequacy of governance. In the area of sanitation public and private concerns and manners of addressing them come together. Defecation, which is a private and intimate activity, constitutes a public problem both in terms of health risk and environmental pollution. It may, therefore, be expected that the "blurring of boundaries and responsibilities" and the importance of "self-governing networks of actors", which Stoker (1998: 18) mentions as key elements of governance, will manifest themselves in the management of human waste. Governance, with its emphasis on (governmental support of) autonomy of actors, 
reminds one of a concept, which was popular a few decades ago in the domain of health policy: Primary Health Care (PHC). The term is no longer used in policy plans as it conjures up a too-optimistic picture of people's ability and determination to solve their problems by their own means. The term also assumes an overly positive image of the determination of governments to contribute to sustainable improvement at the level of local communities.

More than ten years ago, one of us argued that PHC meant different things to different stakeholders with different (often conflicting) interests at different levels of social and political organisation (Van der Geest et al. 1990). For representatives of international agencies, PHC was a - somewhat utopian - ideal to realise "Health for all by the year 2000 ", a prescription for health - and overall - development from below. For national governments in developing countries, PHC was first of all a strategic term and buzzword to increase foreign financial aid and reduce spending on local health care. For local inhabitants, PHC meant a cut in government support, "second-hand health care", and "forced self-reliance".

We do not want to fall into cynicism but cannot help wondering if "governance" is the reincarnation of abandoned policies of the past, such as PHC (and "Community Development"2). In this paper we will present and discuss two cases of sanitation in Ghana, one rural, one urban, and suggest that the poor management of human waste epitomises the limitations and failures of governance - or PHC - in present-day Ghana.

Public and private toilets in accra

12 Policy-makers of the Accra Metropolitan Area (AMA) responsible for liquid waste management face a dilemma : should the y promote and improve public toilet facilities in the city or should the y encourage and assist inhabitants in having their own toilet in the house ? Many homes in Accra do not have their own toilet. Toilets and bathrooms in houses in the central business areas have sometimes been converted into rooms and stores. As a result, the residents of such homes rely on public toilets, which may be inadequate and face serious maintenance problems. According to the metropolitan authority, public toilets are meant for visitors to the city and not for residents. The opposite is the rule however. Public toilets have become permanent features for many residents in Accra as places to ease themselves. Accra faces acute sanitation problems. These are manifested in unsanitary conditions in and around most of the public toilets, poor and dilapidated infrastructure for liquid waste management, inadequate funding for maintenance, poor sanitary habits, deficient management of existing toilet facilities, indiscriminate defecation in open spaces, into water bodies and drains, irregular collection of liquid waste from sep tic and other storage tanks, as well as from pan latrines, and limited connections from houses to the central sewage system.

Present situation

The existing toilet facilities in Accra, both private and public, include pan (or bucket) latrines, pit latrines, septic tank latrines, KVIPs (a particular type of storage tank), and water closets (WCs) with or without connection to the central sewage system. There are two types of public toilet ownership, namely (i) those built by the local authority, and (ii) those built by private firms and individuals for commercial purposes. The types and numbers of public toilet facilities available in the six, sub-metropolitan assemblies of AMA, are as follows: Ashiedu Keteke 26, Ablekuma 40, Osu Klottey 19, Okaikoi 11, Ayawaso 28, and Kpeshie 34. Privately built public toilets are few in number. The public toilet facilities are inadequate compared to the size of the population lacking toilet 
facilities in their houses. Long queues could be observed during early morning and evening rush hours. According to residents, some people defecate in empty spaces because of (i) the cost of a public toilet visit, (ii) a lack of toilets in the vicinity, (iii) long distances between public toilets and their houses, and (iv) the untidiness of the toilet facilities. In May 1999, user-fees ranged from $\$ 100.00$ to $\$ 150.00$ per visit, depending upon the facility. The AMA determines the user-fees.

The existing infrastructure of the Accra central sewage system is inadequate. In 1999, there were less than 1,000 units connected to the central sewage system (GW\&SC 1999). In most places, the infrastructure for waste management is either non-existent or in a deplorable state. As Akuffo (1999) noted, there are about 18 sewage systems and sewage treatment plants in Accra, but none of them is operating according to plan. The system that was built for Central Accra in the early 1970s by the Busia government is no longer adequate. There are few connections and links to water to en able flushing are insufficient. Waste management has broken down due to a lack of human, logistic and financial resources. The present approach based on harangue, sermonising and clean-up campaigns is not helpful. There is a need for injection of capital into the system, including strengthening existing institutions. Investments in plants and equipment in the present circumstances of complete institutional breakdown are clearly not the right approach.

If availability of toilet facilities and the method of removal and disposal are indications of level of development, the city of Accra cannot be rated high on the scale of development. A survey of toilet facilities in Accra by the AMA in 1992 showed that :

- $40 \%$ of the population had access to private toilets discharging into septic tanks or cesspools ;

- $25 \%$ used public toilets where a fee is charged per visit. There are about 127 public toilets in Accra ;

- $20 \%$ still used private, pan latrines ;

- $5 \%$ had access to private KVIPs and

- $10 \%$ of the population had no access to any toilet facility and defecated in open spaces.

The critical shortage of toilet facilities in Accra is obvious from these figures. Let us briefly look at the various types of services.

Cesspit service

The AMA and private firms carry out cesspit service with suction trucks. In addition to these, other organisations such as the Volta River Authority, the security services (army, police, prisons, and fire service), the University of Ghana, and the Ghana Civil Aviation Authority, etc., run their own suction trucks to empty the cesspits of staff bungalows and a few private houses.

18 These organisations discharge their waste at the Waste Management Department's (WMD) treatment plants.

Pan latrine service

19 Night-soil collectors empty the bucket or pan latrines during the night. Liquid waste collection from pan latrines has been fully privatised since December 1987. The Waste Management Department provides surface and underground storage facilities and collection vehicles to empty the tanks. New pan latrines are not allowed. People have been ordered to convert the old ones to KVIP latrines or to use available public toilets. KVIP latrines 
20 Most of the initial KVIPs installed at several city locations as public and private toilets were pre-financed through a revolving fund set up by the German Technical Co-operation Unit (GTZ) to support the phasing out of pan latrines. The major push towards conversion from pan latrines to KVIPs began in late 1987 with the establishment of the Urban Sanitation Improvement Team (USIT) in the Waste Management Department. This unit comprises representatives of the Medical Officer of Health and the Metropolitan Engineer to facilitate approval of building permits for conversion from pan latrines to KVIP latrines. It was then envisaged that the promotion of the project would be maintained and addition al funds secured to enlarge the revolving fund for the project. The KVIPs were supposed to be built in areas with porous soil so that the liquid found in the toilet could be absorbed by the soil, leaving the scum to be scooped out for use as manure in gardening and agriculture. Unfortunately however, the soil in Accra is clayish and as a result cannot absorb the liquid from the toilet as expected. The toilet is therefore always wet and needs dislodgement by suction pumps.

Public septic tank latrines

21 Most of the public toilets in the city have septic tanks. They are particularly found in areas without a central sewage system. The tanks have to be emptied periodically by suction trucks.

Liquid waste treatment sites

22 The liquid waste from septic storage tanks, together with the waste from the central sewage system, is collected at three treatment plants. These are found at Achimota (with a capacity of 55000 metric tons), Teshie (10000 metric tons), and Korle Gonno (33000 metric tons). However, these treatment plants find themselves in various degrees of disrepair and are not functioning properly.

Central sewage system

23 The central sewage system is provided, controlled, maintained and owned by the Ghana Water and Sewage Corporation (GW\&SC). The sewage infrastructure requires tremendous levels of capital outlay. The areas with fee-based toilet facilities connected to the central sewage line are Accra Central, Tudu, Central Lorry Park, the Ministries, Osu and Dansoman. Dansoman has its own central sewage system which is not connected to the rest. The Dansoman sewage system was constructed during the Dansoman Housing Project by the Acheampong government. This line is connected to a treatment plant which flows to the sea.

Private (household) toilets are owned, maintained and used by individuals while public toilets are operated on a commercial basis. Toilet facilities with connections to the central sewage system pay connection fees to the GW\&SC. This includes registration fees and monthly charges. Owners of toilet facilities without connections to the central sewage system pay various types of fees i.e. for removal and transportation of their liquid waste. Service providers are periodically engaged to remove the waste from toilets with septic storage tanks. Various fees are paid to the service providers depending on the facility's type and capacity.

Removal and transportation of waste

The type of toilet facility determines the way the waste is removed and transported to disposal sites. Liquid waste from toilet facilities with sewage connections is transported automatically from the toilet facility to the disposal point through the sewage system. Night-soil collectors empty pan latrines and carry the waste to central collection points 
(cesspools). The big containers are normally lifted at night and emptied at a treatment plant or approved disposal site.

Toilets with septic storage tanks are emptied by service providers i.e. WMD, private agencies or in the case of Labadi, by a community-based organisation (La Mansaamoo Kpee). Quasi-public organisations such as SSNIT, the University of Ghana, (Legon), and the security services; (army, police, prisons, etc.) have their own liquid waste collection and transportation services to designated sites.

Institutional arrangements for collection and removal of liquid waste in the metropolitan area differ and can be summarised as follows: (i) cess pit emptying service for private house ho Ids with a water carriage latrine system, (ii) public toilets' dislodgement for septic tank latrines, KVIPs, and WCs, (iii) surface containers for pan latrines, and (iv) the central sewage system. Each type of household facility has its own specific arrangement for removal.

The frequency of waste removal is directly linked to the type of facility and its capacity. Pan latrines are emptied twice or thrice a week to a central cesspit surface container, which in turn is removed every night, hence the name "night-soil". However, irregular waste collection is the rule rather than the exception. Toilet facilities without a connection to the central sewage system (WCs, KVIPs, and septic tank latines) are emptied when they are full, which varies from once in six months to once in three years.

Mode of payment

29 There are different modes of payment in the liquid waste management sector. Owners of toilet facilities with a sewage connection pay registration and monthly charges to the GW\&SC. Owners of all other categories of toilets without a connection to the central sewage system pay fees to other service providers. The service providers include the AMA, AMA's accredited agents, non-AMA accredited agents, and community-based organisations, e.g. the La Mansamoloo Kpee. Quasi-public organisations such as: Cocobod, SSNIT, and the University of Ghana, which provide their own services, pay discharge fees to the AMA. The security services (army, police, prisons, and fire service), which also have their own service trucks do not pay any fees for the discharge of waste. All categories of public/communal toilets with or without connections to the central sewage system pay registration and licence fees to the AMA to operate as a commercial entity in the metropolitan area. Owners or managers of all non sewage public/communal toilet facilities pay dislodgement fees to service providers. Operators of toilets owned and operated by the AMA pay all revenues to the AMA. Operators of privately managed AMA toilet facilities pay dislodgement fees to service providers including the AMA.

The owners of communal toilets charge a user-fee per visit. Income generated from the user-fees is used for the facilities' maintenance and operation. The fees are subject to approval by the AMA. In most cases, however, particularly in the private-private arrangements, the rates are fixed by the service provider without the involvement and consent of the AMA, but within its approved rates. The fee may differ from one type of facility to the other. For example, the fees for WCs differ from those for a septic tank latrine or KVIPs. WCs with a sewage connection attract higher rates than those without water or with frequent water shortages. Factors such as cleanliness, environment, atmosphere, presence of toilet paper rolls, etc. all affect the price of the service. Most 
people settle for modest services with affordable prices even though ail the service consumers prefer WCs with a sewage connection.

Monitoring, evaluation and supervision

31 Since the 1990s, the management of publicly owned toilets in the metropolitan area has been decentralised to the lower levels of government whilst others have been privatised. In line with its decentralisation policy, the AMA gave suction trucks and other equipment to the sub-metropolitan districts. Officers were posted to the districts to supervise the day-to-day cleaning of the toilets and to effect better monitoring and evaluation of public toilets. Publicly owned communal toilets are now under the supervision of the sub-metropolitan assemblies. The toilets are controlled and supervised by District Cleansing Officers, who, in turn, are supervised by the Environmental Health Technologist at the headquarters. The operators are expected to clean the toilets daily. Cleansing Officers from the WMD inspect the public toilets' premises from time to time. Every two or three years, the septic tank of a public toilet is emptied.

The Environmental Protection Agency (EPA) helps to provide guidelines on monitoring public toilets. The EPA periodically inspects treatment plants and leaches at dumping sites. The WMD liaises with the Metropolitan Health Department to sue waste and sanitary offenders. The Health Department assists in environmental health education. Standard Boards also help by checking periodically for items that have expired and recommend their destruction. Private organisations such as SSNIT, the Cocoa Board, the police, and other security agencies that handle their own liquid waste meet periodically with the WMD to discuss liquid waste management strategies. There is also constant interaction between the AMA and pan latrine contractors.

However, a lack of funds at the sub-metropolitan level makes it difficult to manage and maintain equipment, including trucks. Therefore, even though the operation of waste management has been decentralised to the lower levels, the day-to-day management is still being directed from the WMD head office. There are plans to further privatise the system to ensure a more effective means of service delivery.

The most feasible, achievable and efficient system

Though the most efficient system of liquid waste management is the WC connected to the central sewage system, the majority of the people do not have access to this type of facility. Only a limited number of WCs are connected to the central sewage system. For areas without a sewage system, WCs with a septic storage tank provide the best alternative.

Irregular water supply in some areas affects their operation, however. For poor and deprived areas, the KVIP is the best alternative since it does not require water to function. However, the initial cost of building a KVIP and its maintenance, including the periodic removal of waste put it beyond the reach of many households. In view of this, policy-makers have embarked upon measures to increase and improve public toilets for the large portion of the population, whilst at the same time, encouraging increased use of household, private toilets.

36 According to some people, the real problem surrounding the management of public toilets in the past was not so much centralisation per se, but the fact that there was insufficient money to run them efficiently. 

proper government funding. The problem has somehow been reduced through the introduction of user-fees since the 1980s, decentralisation of the waste management system since 1992, and privatisation of some aspects of liquid waste management some years later.

Public toilets are operated either by contracting out or franchising. The invitation extended to private firms and individuals to build and operate public toilets on a commercial basis has greatly helped liquid waste management. As long as the economic situation of the majority of the people remains very poor, public toilets will remain an essential feature of Accra's liquid waste management.

Stakeholders

Three types of actors or stakeholders can be identified : service providers, consumers and policy-makers. The survey showed that service providers are satisfied with the present functioning of the institutional arrangements, but that $87 \%$ of the consumers prefer WCs connected to the sewage system. The position of policy-makers, as we will see, is ambivalent.

Service providers

There are three main types of service providers, namely (i) providers of toilet facilities, (ii) managers of toilet facilities, and (iii) those who remove and transport liquid waste (i.e. night-soil collectors and suction truck operators). Each of these has its own interests, depending on how much it gains from the service.

41 Public toilet service providers want more public patronage in order to make higher profits. Public toilet operators are content with the institutional arrangement for provision, utilisation and payment, cost recovery, and cost sharing arrangement, even though there is room for improvement. The housing code requires every household to have its own toilet, but taking into account the profits earned from the operation of public toilets and the lucrative payments of user-fees for removal services, the discontinuation of public toilets is unlikely to occur in the near future. Suction truck operators want households to continue using septic storage tanks and public toilet operators want residents to continue relying on their facilities.

Consumers

Owners of toilets with a sewage connection pay fees and monthly charges to the Ghana Water and Sewage Corporation (GW\&SC). For ail other categories of toilet facilities without connection to the central sewage system, suction truck operators empty the storage tanks periodically. The removal of liquid waste is carried out by either the WMD or by private contractors. However, rich households prefer WCs connected to the central sewage system to spare them the inconvenience and agony of searching for service providers to empty their septic storage tank whenever it is full. Besides, when the toilet is removed or dislodged, it leaves a terrible stench in the area for hours, if not days. Pan latrines needs emptying twice or thrice a week. Irregular collection poses a severe sanitation problem, including stench. Flies are always abundant in the place. Besides, pan latrines have outlived their usefulness in the city and are a nuisance, particularly to the immediate neighbours. If toilet facilities are not emptied regularly, they pose health hazards and become breeding grounds for vectors of disease.

Bulletin de l'APAD, 23-24 | 2002 

waste management unless it is backed with fiscal transfers to enable lower government structures to manage the responsibilities entrusted to them. Some residents want wider coverage by the central sewage system whilst others expect more from strict enforcement of housing regulations : new houses should have their own private toilets. At the same time, more and decent public toilets with neat and pleasant surroundings must be developed to take care of those without access to private toilets. As the operation of public toilets becomes more lucrative, so will the corruption in its revenue management. Ghana has a poor maintenance culture. The situation is worst in the waste management sector. The majority of the people think that the decision to lease or contract out the management of government-owned public toilets is the best policy so far. This has indeed led to improvements in the conditions of most of them. Privatisation has led to competition in the management of public toilets and suction truck service provision. This will improve even further, of course, if revenues for their maintenance are handled properly. Contract awards should therefore be made in terms of efficiency, transparency and capability. house, one toilet' is not realistic for the time-being. Financial resources, both public and private, would not tolerate such a programme. For the poorer areas of the metropolis, therefore, the local government should embark on a thorough improvement of public toilet facilities. "Improvement" includes among other things : cleaner sanitary conditions, better management, easier access and more privacy. 
Privatisation and external contracting, if executed in a "humane" and reasonable manner, can help to achieve this objective.

Public and private toilets in a rural community

Defective toilet facilities are particularly depressing in densely populated places such as the townships of Accra. The lack of facilities in rural places causes less direct inconvenience if 'nature' is near and mercifully hides and 'digests' the traces of human pollution. Moreover, many of the inhabitants are - at least part-time - farmers and have the possibility to relieve themselves on their way to the farm or on their farm. The small town of Kwahu-Tafo (in Southern Ghana), where one of the authors carried out anthropological fieldwork, may serve as an example of rural coping - and lack of coping - with inadequate liquid waste management.

There are two public toilets, each with twelve squatting holes (six for each sex), in Kwahu-Tafo. This means there are just 24 public facilities for the entire town of about 5 000 inhabitants. Some people have to walk about ten minutes to reach a public toilet (to and fro twenty minutes). In addition there are semi-public toilets in two schools, which can be used by both teachers and pupils. The number of private latrines (almost all bucket latrines) is unknown. The sanitary inspector estimates their number at sixty. Finally, there are about ten private pit latrines and ten WCs, one in the chief's house, the others in the Catholic mission and the teachers' bungalows of the Technical School. In and around public toilets

51 It is impossible to say how many people are in fact using the public toilets. Estimates vary from one-third to eighty percent of the population, which in absolute figures would be 1000 to more than 4000 people. Unknown is also the number of people who don't use toilets at all but ease themselves in the "bush" at the edge of town or on the way to their farm. Some people defecate into a plastic bag and dump the bag somewhere out of sight.

52 The combination of plastic and human faeces is no doubt the most appalling form of pollution taking place in Ghana. Apparently some people view the plastic bag as a handy, portable and disposable, private toilet. It seems an attractive compromise : one can defecate at home and yet one is not stuck with the unpleasant presence of a permanent toilet in the home.

53 If we take a conservative estimate of forty percent of the people visiting the public toilet, it means that every day, about 2000 people use 24 holes, that is almost ninety per hole, per day. Taking into account that both toilets are closed from about 9 pm until 5 am, one can conclude that the holes are occupied every five minutes. On the average both public latrines would receive about 1000 visitors per day. When we discussed this with the caretaker of one of the latrines he estimated a number of only about 200-300. He based his calculation on his daily income. Whatever the exact number, it is not surprising that there are queues early in the morning as most people prefer to ease themselves before they start the day.

54 For elderly people the way to the public toilet seems particularly painful. It may be far and the conditions do not befit their status of respected elder. Most elders therefore use a private latrine, either in their own house or in that of a kind neighbour. They are also likely to avoid the morning rush hour if they have to go to the public toilet (cf., Van der Geest 2002a). 

and have other ambitions. In 1998 there was only one Kruni in Kwahu-Tafo. The man was getting old and could hardly cope with the work. He had no successor. Two years later we held some interviews with him and observed his style of working and his way of protecting himself against the stench and the dangers of his job. By then he was sharing the work with another Kruni (Van der Geest 2002b). It is unlikely that ail bucket 
latrines will have been replaced by pit or KVlP latrines (as the official policy stipulates) by the time these two men stop their work as night-soil collectors.

Discussion and conclusion : governance of daily life

61 There is hardly any activity, which fits the theme of "Governance of daily life", as well as the daily visit to a toilet. Defecation should take place everyday. One "missed day" constitutes a health risk in the popular cultural perception (Osei 1987, Van der Geest 2003). If we accept human "well-being" as the best criterion of good governance, sanitation presents itself as a crucial test case of governance. In the quality of toilet facilities we discern medical as well as social and political indicators of welfare. Toilets are significant markers of social status and political power. Various authors, from Douglas (1966) to Curtis (1998) and Green (1999), have argued that experiences of dirt and cleanliness have far-reaching consequences for self-esteem, social identity and physical and mental health. What conclusions can be drawn from the two cases in this paper?

Our observations on the management of human waste in Accra as well as in the rural community of Kwahu-Tafo show a lack of concern and initiative with regards to sanitation both from the government and the local community. It is mainly the "invisible hand" of small entrepreneurs that succeeds in bringing about modest improvements in the quality of sanitation. Let us briefly look at the different actors.

63 Proper sanitation, one would expect, is one of the most convincing legitimisations of politics. Individual initiative can hardly achieve building effective infrastructural facilities to dispose of human waste, but state resources can. Public authorities have the "chance" to prove their concern about the well-being of their citizens by providing sanitary amenities and thus strengthening their political support in the community. That "chance", however, is hardly utilised. Local authorities, both in urban and rural areas, have a poor record when it comes to the building of sanitary facilities.

Three of the four reasons suggested by Gewald $(2000: 144)$ to account for the lack of political will to improve sanitary conditions in Windhoek almost one hundred years ago, still apply to Ghana today. Financial constraints and cultural disgust are obvious factors - or excuses - to explain the government's inertia in sanitary matters. Most shocking is the fact that the racist attitude of the South African government towards the Herero population in the 1920 s can still be detected in the discriminatory behaviour of Ghanaian politicians to the poor members of their society. Having access to their own clean private toilets, they close their eyes to the squalor of public facilities on which their less fortunate co-citizens rely. "Squeamish unease" and outright discrimination conveniently merge into politics of neglect (see also Frantzen \& Post 1999).

65 Surprisingly, local inhabitants and users of public facilities also do very little to improve the situation. If good governance involves both "governors" and ordinary citizens, we may conclude that both sides lack political initiative in this respect. We call this lack of initiative "surprising" because it seems to contradict a strong cultural concern about cleanliness as a physical and moral state. During our visit to the public toilets in Accra people complained bitterly about the authorities' lack of concern and their failure to improve sanitary conditions, but they themselves showed no initiative to do something about it either. Their concern about cleanliness did not motivate them to take sanitary governance into their own hands ; it rather seemed to discourage them from doing anything. Elsewhere one of us (Van der Geest 1998) has proposed that 
cultural rules of cleanliness have led to the paradoxical situation that people cope with the daily . confrontation with dirt by keeping defecation at bay, both geographically and mentally. Governance of sanitation is mainly a matter of not thinking about it. Ironically, this applies to political authorities as well as to local inhabitants.

Entrepreneurs who are able to make a profit out of the management of public toilets and the collection of human waste from private bucket latrines provide the best "governance". The slight improvements which have been achieved in the management of liquid waste seem to be mainly the result of the incentives of privatisation. Private caretakers of public toilets have tried to make the visit to the toilet less unpleasant by keeping the place relatively tidy. Examples of this have been reported from Accra (Obirih-Opareh 2001) and the rural town of Kwahu-Tafo (Van der Geest 2001), but also from the city of Kumase (Frantzen \& Post 1999, Post 2001).

The performance of the night-soil collector (van der Geest 2002b) is another example of private enterprise. Ironically, it is the inadequacy of public services responsible for the further disposal of human waste which thwarts the good performance of the toilet manager. In Accra failure to empty the storage tanks in time causes an overflowing of the toilet holes. In Kwahu-Tafo they deposit the contents of the KVIP tank right behind the toilet turning the place into a mess.

From the limited evidence of our observations in Accra and Kwahu-Tafo we are inclined to conclude that both policy-makers and users of public toilet facilities have their "reasons" to remain inactive with regard to the improvement of public toilets but that some effect may be expected from the privatisation of public toilets. Privatisation should not be restricted to the management of the facility, however, but also include the further removal of liquid waste.

\section{BIBLIOGRAPHY}

Akuffo S.B., 1999, The sanitation riddle. Daily Graphic, Wednesday : 7.

Curtis V., 1988, The dangers of dirt : Household, hygiene and health. Wageningen : Agricultural University Wageningen, Dissertation.

Douglas M., 1966, Purity and danger. An analysis of concepts of pollution and taboo. Harmondsworth : Penguin.

Foster G.M., 1982, Community development and primary health care : their conceptual similarities, Medical Anthropology, vol. 6, n 3 :183-95.

Frantzen A. \& Post J., 1999, Wei en wee van de publieke plee. Het voorbeeld van Kumasi, Ghana. Medische Antropologie, vol. 11, $\mathrm{n}^{\circ} 1: 84-97$.

Gewald J.-B., 2000, "We thought we would be free..." Social-cultural aspects of Herero history in Namibia 1915-1940. Koln : Rüdiger Koppe Verlag.

Green E.C., 1999, Indigenous theories of contagious disease. Walnut Creek : Altamira Press. 
Lea R., 1999, "The shitful body" : Excretion and control. Medische Antropologie, vol. 11, n $1:$ 7-18.

Obirih-Opareh N., 2001, "Public or private? A policy dilemma of liquid waste management in Accra." In : Van der Geest \& Obirih-Opareh 2001 : 13-24.

Osei Y., 1987, Traditional medicine among the Akan of Ghana. Unpublished Ph.D. thesis. Medical Faculty, Ruprecht Karl University, Heidelberg.

Post J., 2000, "Managing liquid waste : The case of public toilets in Kumasi." In : Van der Geest \& Obirih-Opareh $2001: 25-34$.

Stoker G., 1998, "Governance as theory : Five propositions." ISSJ 155 : 17-28.

Van der Geest S., 1998, "Akan shit : Getting rid of dirt in Ghana." Anthropology Today, vol. 14, n 3 : 8-12.

- 2001, "Toilets, privacy and perceptions of dirt in Kwahu-Tafo" In : Van der Geest \& Obirih-Opareh $2001: 5-12$.

- 2002a, "The toilet : Dignity, privacy and care of elderly people in Kwahu, Ghana." ln : S. Makoni \& K. Stroeken (eds) Ageing in Africa : Sociolinguistic and anthropological approaches. London :

Ashgate : 227-44.

- 2002b, "The night-soil collector : Bucket latrines in Ghana." Postcolonial Studies, vol. 5, $\mathrm{n}^{\circ} 4$ : 197-206.

- 2003, "Healthy bowel movements in Kwahu-Tafo : A brief note." Viennese Ethnomedical Newsletter, in press.

Van der Geest S., Obirih-Opareh N. (eds), 2001, Toilets and sanitation in Ghana: An urgent matte. Accra : Institute of Scientific and Technological Information (INSTI), CSIR, Ghana.

Van der Geest S, Speckmann J.D., Streefland P., 1990, "Primary health care in a multilevel perspective : towards a research agenda." Social Science \& Medicine vol. 30, n 9 : 1025-34.

\section{NOTES}

1.This paper draws upon an earlier publication on toilets and sanitation in Ghana (Van der Geest \& Obirih-Opareh 2001).

2.Two decades ago Foster (1982) questioned if PHC was the reappearance of Community Development in a different garment.

3.A Kruni (plural : Krufoo) was originally someone from Sierra Leone. but presently most night-soil collectors are from Northern Ghana or Burkina Faso.

\section{AUTHORS}

\section{SJAAK VAN DER GEEST}

Medical Anthropology Unit and AGIDS, University of Amsterdam. 


\section{NELSON OBIRIH-OPAREH}

AGIDS, University of Amsterdam 